\title{
Primary malignant peripheral nerve sheath tumour of the trachea: a case report and literature review
}

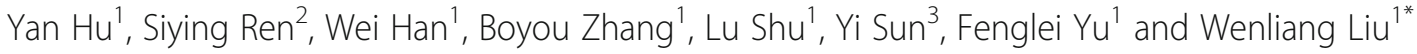

\begin{abstract}
Background: Malignant peripheral nerve sheath tumours (MPNSTs) of the trachea are extremely uncommon neoplasms with unknown genetic and clinical profiles. Only individual cases have been reported in the literature to date.

Case presentation: Here, we present a rare case of a 61-year-old female patient with a primary MPNST of the trachea who complained of irritating cough and progressively increasing breathlessness for 4 weeks. This patient initially underwent intraluminal resection of the mass and was misdiagnosed with clear cell sarcoma. Less than a year later, the mass relapsed, and the obstructive symptoms reappeared and gradually worsened. Debulking of the endotracheal tumour mass was performed once again, and an MPNST was definitively diagnosed. Open sleeve tracheal resection and tracheoplasty were later performed with curative intent. This patient was alive without recurrence at her six-month postoperative follow-up. We also compared the clinical outcomes of previously reported cases of MPNSTs and our case.

Conclusions: This paper emphasizes that thoracic surgeons should be aware that malignant peripheral nerve sheath tumours of the trachea can be misdiagnosed in clinical practice and must be included in the differential diagnosis of tracheal neoplasms.
\end{abstract}

Keywords: Malignant peripheral nerve sheath tumour, Trachea, Misdiagnosis

\section{Background}

Primary tracheal cancer is one of the rare malignancies in the upper airway, accounting for only $0.1-0.4 \%$ of all newly diagnosed tumours. Currently, there is no validated staging system for diagnosis, survival prediction, or management. The prognosis of patients diagnosed with tracheal cancer is dismal. MPNST commonly occurs in the extremities. Primary MPNST of the trachea has rarely been reported in the literature. We herein present a rare case of an MPNST in the trachea initially misdiagnosed as clear cell sarcoma and present a literature review of previously reported cases of tracheal MPNSTs.

\footnotetext{
* Correspondence: liuwenliang@csu.edu.cn

'Department of Thoracic Surgery, Second Xiangya Hospital of Central South University, No. 139 Renmin Road, Changsha 410011, China

Full list of author information is available at the end of the article
}

\section{Case presentation}

A 61-year-old female patient was admitted to a local hospital in August 2018 because of irritating cough and progressively increasing breathlessness over a duration of 4 weeks. Rinopharyngeal thoracic computed tomography scans showed severe luminal obstruction of the middle upper segment of the trachea caused by a mass. Rigid tracheoscopy was performed, revealing an endotracheal mass with a wide base originating in the posterior lateral wall of the trachea occluding $75 \%$ of the lumen. The tumour was then endoscopically resected through high-frequency electric coagulation, cutting and argon plasma coagulation in that hospital. Postoperative pathology gave a misdiagnosis of clear cell sarcoma of the trachea. The patient was free of any discomfort until April 2019. Then, she complained of the reappearance 
of nonproductive cough and shortness of breath, which gradually worsened.

This patient was subsequently admitted to our hospital in June 2019. Cervicothoracic CT scans revealed a $2.5 \times 1.8 \times 1.6 \mathrm{~cm}$ mass arising from the right posterior lateral wall of the trachea approximately $4.5 \mathrm{~cm}$ below the glottis and $4.7 \mathrm{~cm}$ above the carina with a suspicious extension of the oesophageal wall (Fig. 1). Bronchoscopy was performed, showing a cauliflowerlike mass obstructing $60 \%$ of the tracheal lumen. After obtaining biopsies, an in-site exfoliated cell smear was performed, which indicated suspicious tumour cells with nuclear atypia. Tumour debulking was then performed through high-frequency electric coagulation and cutting to alleviate airway obstruction. This patient gained obvious relief from the obstructive symptoms postoperatively.

Histopathology revealed diffuse spindle cells with pleomorphic nuclei and translucent cytoplasm. Mitoses and necrosis were noted. The tumour cells were positive for S100 (Fig. 1), SOX-10, and vimentin but negative for pancytokeratin, SMA, desmin, transcription factor E3 (TFE3), and master myogenic regulatory factor (MyoD1) by immunohistochemistry. Melanocyticspecific markers, such as HMB45 and melan-A, were also negative. Thus, taken together, the morphologic and immunohistochemical features favoured the diagnosis of a malignant peripheral nerve sheath tumour (MPNST). Owing to the epithelioid morphology and diffuse S100 immunoreactivity, an unusual variant of an epithelioid MPNST was therefore determined. The tumour of this patient was further classified as a sporadic MPNST since no related signs of neurofibromatosis type 1 (NF1) were noted.

Because of the rarity of this disease, this case was discussed in a multidisciplinary tumour board meeting. A consensus was reached, and this patient was later treated with tracheal resection and tracheoplasty through a median sternotomy approach. Intraoperative exploration did not find obvious neoplastic involvement of the oesophageal wall. The length of the resected trachea was approximately $3 \mathrm{~cm}$. Both margins turned out to be negative. The airway was reconstructed with a posterior continuous suture and an anterior row of interrupted sutures, and the anastomosis was covered with autologous thymus tissue. This patient experienced an uneventful postoperative course. At her six-month postoperative follow-up, she continued to do well without complications or evidence of recurrence (Fig. 1). The patient is scheduled to receive regular follow-up evaluations every 6 months using computed tomography and bronchoscopy to monitor for recurrence.
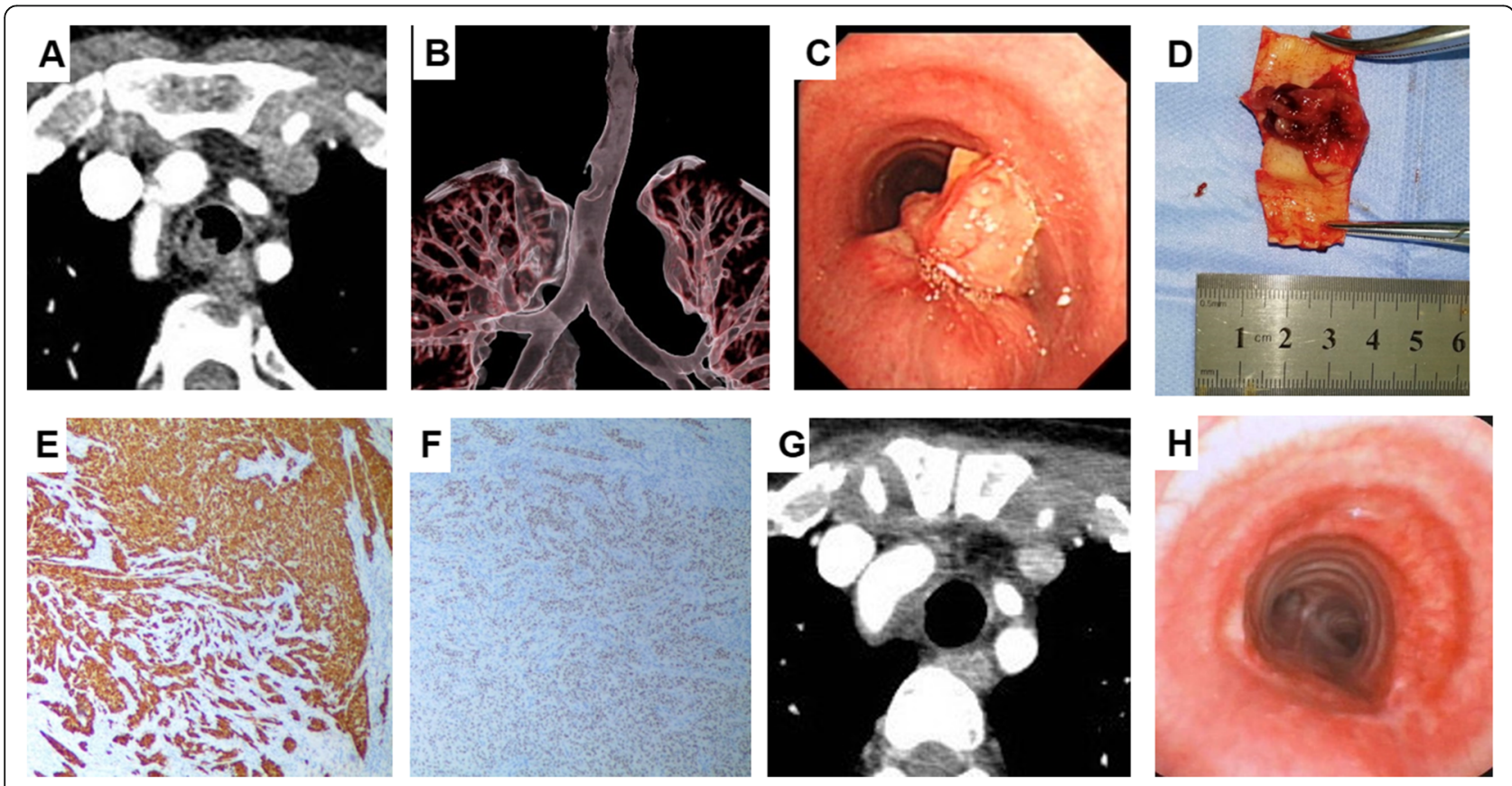

Fig. 1 A case of a tracheal malignant peripheral nerve sheath tumour. a Preoperative thoracic CT scans reveal a tumour arising from the right posterior lateral wall of the trachea; $\mathbf{b}$ Reconstruction of the airway demonstrated a tracheal defect approximately $4.7 \mathrm{~cm}$ above the carina; $\mathbf{c}$ Bronchoscopy showed a cauliflower-like mass obstructing $60 \%$ of the tracheal lumen; $\mathbf{d}$ View of the resected tumour; e The tumour cells are positive for S100; $\mathbf{f}$ The tumour cells are positive for SOX-10; $\mathbf{g}$, $\mathbf{h}$ Postoperative thoracic CT scans and bronchoscopy at the six-month follow-up showed no local recurrence 


\section{Discussion}

Primary tracheal cancer is one of the rare malignancies in the upper airway, accounting for only $0.1-0.4 \%$ of all newly diagnosed tumours, with an incidence of 2.6 new cases per 1,000,000 people per year [1]. Owing to its rarity and the difficulties of diagnosis via chest X-ray, tracheal cancer is usually misdiagnosed. CT scans together with tracheobronchoscopy form the mainstays for diagnosing and staging primary tracheal cancer. Squamous cell carcinoma is the predominant histological type of tracheal cancer, followed by adenoid cystic carcinoma and neuroendocrine tumours [2]. Tracheal cancer, when large, typically presents with obstructive symptoms such as dyspnoea, stridor, wheezing, cough, and haemoptysis.

Currently, no validated staging system exists for diagnosis, survival prediction, or management. The prognosis of patients diagnosed with tracheal cancer is dismal, with 5-year and 10-year overall survival rates of 5-15\% and $6-7 \%$, respectively [3]. Patients with an old age, large tumour size, advanced tumour extension and no surgery may have a worse prognosis [4]. Primary tracheal cancer can be treated with surgery, endotracheal resection by various techniques, and radiotherapy [3]. Surgical resection is the treatment modality that offers the best chance of achieving a long-term cure. Endotracheal treatment is tailored to debulk the tumour mass for patients with acute airway obstruction prior to definitive surgery or as a palliative regimen in patients with unresectable disease. Radiotherapy is indicated as adjuvant therapy after surgical resection, as primary therapy in patients with inoperable or unresectable disease and as palliative therapy for severe symptoms.

Malignant peripheral nerve sheath tumours are highly aggressive neoplasms, accounting for 5 to $10 \%$ of softtissue sarcomas, and can be sporadic, be observed in patients with neurofibromatosis type 1, or develop post irradiation [5]. Owing to its morphological heterogeneity and lack of definitive markers, MPNSTs can be easily misdiagnosed as other malignancies that exhibit similar histologic features, such as a variety of sarcomas (synovial sarcoma, rhabdomyosarcoma, leiomyosarcoma, dedifferentiated liposarcoma, clear cell sarcoma, and dermatofibrosarcoma protuberans) as well as non-mesenchymal tumours (especially melanoma) [6]. Lehnhardt et al. showed that the false primary diagnosis rate of MPNST was $78.4 \%$, which was the highest among false diagnosis rates of the eight most frequent sarcoma types [7]. A recent study showed that $18.1 \%$ (29 out of 160) of initial diagnoses of MPNST had to be revised during reassessment [8].

The pathogenic mechanism of MPNST remains to be determined. The loss of NF1 and p53 are considered the most frequently reported gene mutations in MPNS $\mathrm{T}$ and are responsible for malignant transformations arising [9]. Accumulating evidence has indicated the existence of a multistep aggregation of additional mutations of multiple tumour suppressors, cell cycle dysfunctions, and signalling regulation genes, resulting in signalling cascade disorders and receptor tyrosine kinase amplification [10].

MPNSTs commonly occur in the proximal portions of the extremities. An MPNST arising primarily from the trachea, however, is rarely seen. To the best of our knowledge, only three cases of primary MPNSTs of the trachea have been described in the literature [11-13]. The clinicopathological features of the previously reported cases and our case are summarized in Table 1. Epithelioid MPNSTs, an uncommon histologic variant of MPNSTs, constitutes less than $5 \%$ of MPNSTs and features a distinctive epithelioid morphology and diffuse S100 immunoreactivity [14]. It is noteworthy that this patient was diagnosed with an epithelioid MPNST, which makes this case even more rare.

\section{Conclusions}

Herein, we reported a rare case of a tracheal malignant peripheral nerve sheath tumour with epithelioid

Table 1 Summary of clinicopathological characteristics

\begin{tabular}{|c|c|c|c|c|}
\hline & Shah et al & Neumann et al & Nemade et al & Present case \\
\hline Age/sex & 63/male & $30 / N D$ & 33/male & 61/female \\
\hline Symptoms & Dyspnoea & Dyspnoea & Dyspnoea, stridor & Cough, Dyspnoea \\
\hline Smoking status & Yes & ND & No & No \\
\hline Location & Thoracic trachea & Cervical trachea & Cervical trachea & Thoracic trachea \\
\hline Tumour size $(\mathrm{cm})$ & 2.5 & 1.5 & ND & 2.5 \\
\hline Lymphovascular invasion & Yes & ND & ND & No \\
\hline Treatment & ET, Surgery, RT & ET, Surgery & ET, Surgery & ET, Surgery \\
\hline Resection margins & Negative & ND & Negative & Negative \\
\hline Clinical outcomes & ND & free of disease for 6 years & free of disease for 32 months & free of disease for 6 months \\
\hline
\end{tabular}

ET Endoluminal treatment, RT Radiotherapy, ND Not described 
morphology and reviewed the literature on MPNSTs of the trachea. This paper emphasizes that thoracic surgeons should be aware that malignant peripheral nerve sheath tumours of the trachea can be misdiagnosed in clinical practice and must be included in the differential diagnosis of tracheal neoplasms.

\section{Abbreviations}

MPNST: Malignant peripheral nerve sheath tumour; TFE3: Transcription factor E3; MyoD1: Master myogenic regulatory factor; NF1: Neurofibromatosis type

\section{Acknowledgements}

Not applicable.

\section{Authors' contributions}

$\mathrm{YH}$ drafted and edited this manuscript, assisted in the surgery, and analysed the patient data. SYR edited this manuscript and analysed the patient data. WH, BYZ, LS, and FLY analysed the patient data. YS prepared and assessed the histopathological images. WLL performed the surgery, edited this manuscript, and analysed the patient data. The author(s) read and approved the final manuscript.

\section{Funding}

This work was supported by the National Natural Science Foundation of China (81700070 to Siying Ren), the Natural Science Foundation of Hunan Province (2019JJ30038 to Siying Ren) and the Hunan Province Health Department Research Fund (B2018-0541 to Siying Ren).

\section{Availability of data and materials}

As a case report, all data generated or analysed are included in this article.

\section{Ethics approval and consent to participate}

This study was approved by the Ethics Committee of Second Xiangya Hospital of Central South University, Changsha, China. Written informed consent was obtained from the patient reported in this study.

\section{Consent for publication}

Written informed consent for publication of the clinical details and/or clinical images was provided by the patient.

\section{Competing interests}

The authors have no conflicts of interest to declare in this work.

\section{Author details}

'Department of Thoracic Surgery, Second Xiangya Hospital of Central South University, No. 139 Renmin Road, Changsha 410011, China. ${ }^{2}$ Department of Respiratory and Critical Care Medicine, Second Xiangya Hospital of Central South University, Changsha 410011, China. ${ }^{3}$ Department of Pathology, Second Xiangya Hospital of Central South University, Changsha 410011, China.

Received: 16 May 2020 Accepted: 1 September 2020

Published online: 11 September 2020

\section{References}

1. Honings J, van Dijck JA, Verhagen AF, van der Heijden HF, Marres HA. Incidence and treatment of tracheal cancer: a nationwide study in the Netherlands. Ann Surg Oncol. 2007;14(2):968-76.

2. Urdaneta Al, Yu JB, Wilson LD. Population based cancer registry analysis of primary tracheal carcinoma. Am J Clin Oncol. 2011;34(1):32-7.

3. Honings J, Gaissert HA, van der Heijden HF, Verhagen AF, Kaanders JH, Marres HA. Clinical aspects and treatment of primary tracheal malignancies. Acta Otolaryngol. 2010;130(7):763-72.

4. He J, Shen J, Huang J, Dai C, Liang W, Ye M, et al. Prognosis of primary tracheal tumor: a population-based analysis. J Surg Oncol. 2017; 115(8):1004-10.

5. Zou C, Smith KD, Liu J, Lahat G, Myers S, Wang WL, et al. Clinical, pathological, and molecular variables predictive of malignant peripheral nerve sheath tumor outcome. Ann Surg. 2009;249(6):1014-22.
6. Thway K, Fisher C. Malignant peripheral nerve sheath tumor: pathology and genetics. Ann Diagn Pathol. 2014;18(2):109-16.

7. Lehnhardt M, Daigeler A, Homann HH, Hauser J, Langer S, Steinstrasser $L$, et al. Importance of specialized centers in diagnosis and treatment of extremity-soft tissue sarcomas. Review of 603 cases. Chirurg. 2009; 80(4):341-7.

8. Le Guellec S, Decouvelaere AV, Filleron T, Valo I, Charon-Barra C, Robin YM, et al. Malignant peripheral nerve sheath tumor is a challenging diagnosis: a systematic pathology review, immunohistochemistry, and molecular analysis in 160 patients from the French sarcoma group database. Am J Surg Pathol. 2016:40(7):896-908.

9. Subramanian $\mathrm{S}$, Thayanithy $\mathrm{V}$, West $\mathrm{RB}$, Lee $\mathrm{CH}$, Beck $\mathrm{AH}$, Zhu S, et al. Genome-wide transcriptome analyses reveal p53 inactivation mediated loss of miR-34a expression in malignant peripheral nerve sheath tumours. J Pathol. 2010;220(1):58-70.

10. Upadhyaya M. Genetic basis of tumorigenesis in NF1 malignant peripheral nerve sheath tumors. Front Biosci. 2011;16:937-51.

11. Shah SS, Karnak D, Shah SN, Biscotti C, Murthy S, Mehta AC. Clinicalpathologic conference in general thoracic surgery: a malignant peripheral nerve sheath tumor of the trachea. J Thorac Cardiovasc Surg. 2006;132(6): 1455-9.

12. Nemade H, Nusrath S, Jayakarthik $Y$, Jonathan GT, Chandra Sekhara Rao SL, Fonseca D, et al. Primary malignant peripheral nerve sheath tumor of the trachea: a case report with brief review of literature. Indian J Surg Oncol. 2019;10(2):392-5.

13. Neumann K, Amm S, Krause U, Berghaus A. Malignant schwannoma of the trachea. Hno. 2003;51(9):733-6.

14. Laskin WB, Weiss SW, Bratthauer GL. Epithelioid variant of malignant peripheral nerve sheath tumor (malignant epithelioid schwannoma). Am J Surg Pathol. 1991;15(12):1136-45.

\section{Publisher's Note}

Springer Nature remains neutral with regard to jurisdictional claims in published maps and institutional affiliations.

\section{Ready to submit your research? Choose BMC and benefit from:}

- fast, convenient online submission

- thorough peer review by experienced researchers in your field

- rapid publication on acceptance

- support for research data, including large and complex data types

- gold Open Access which fosters wider collaboration and increased citations

- maximum visibility for your research: over $100 \mathrm{M}$ website views per year

At BMC, research is always in progress.

Learn more biomedcentral.com/submissions 